\title{
What Business Strategy Does and what Management Accounting is Pursuing: A Logistic Regression Analysis
}

Submitted 14/10/19, 1st revision 18/11/19, $2^{\text {nd }}$ revision 29/12/19, Accepted 31/01/20

$$
\text { Joy Lynn R. Legaspi }{ }^{1}
$$

\begin{abstract}
:
Purpose: The aim of this study is to determine whether the time period of business operation, business size, and management accounting tools are predictive of business strategy, customer intimacy, and operational excellence or product leadership.

Design/Methodology/Approach: Multiple logistic regression assessed the relative importance of each factor to each category from 400 participants of SMEs.

Findings: The evidence suggests that managing customers' relationship, product or service cost information, and budgeting are aligned factors for the companies that adopt customer intimacy strategy whereas, budgeting and product or service cost information are the factors for operational excellence strategy. However, product or service cost information provides direct relationship in which the factor increases the likelihood of a positive answer than budgeting and managing customers' relationship in which the factors decrease it, although all of the three factors are significant for the company that adopts product leadership strategy. The findings proved that product or service cost information was useful to all types of customer value proposition and the appropriateness of management accounting information system depends upon the strategies and managerial business assumptions.

Practical Implications: The implementation of strategy is crucial because it requires decision making that needs to be aligned to the company's goals and strive to deliver positive impact to target customers.

Originality/Value: This study provides an indication of the appropriate category, and the positive and negative contributions of different factors for each strategy.
\end{abstract}

Keywords: Customer intimacy, management accounting, operational excellence, product leadeship, small-medium-sized enterprises.

JEL Codes: M40, M41.

Article Type: Research study.

\footnotetext{
${ }^{1}$ Associate Professor, Department of Accountancy, De La Salle University-Manila, happylegaspi@gmail.com
} 


\section{Introduction}

Nowadays managers believe that customers are the most important participants in business. Without customers, the organization loses its ability and its reason to exist (Cole, 2004). They need to have viable strategies for succeeding in the market place. The common order throughout all enterprises is what value propositions that a company can offer to attract customers against it competitors, how to develop strategies that delivers long-term value to stakeholders, and what management accounting information to use as techniques to successfully implement these strategies.

Over the last 50 years, it was descriptively identified that customer satisfaction, cost control, and product quality are the top three choices used to create reasons for customers to choose the company's products and services over their competitors (Foster and Young ,1997). However, Scapens (2006) discovered that most of the study concentrate more on large and public enterprises and encouraged other researchers to investigate about the importance of management accounting information for small-medium-sized enterprises (SMEs), since SMEs represent a major business sector in the industrial world and of great significance in modern countries. In this case, Lucas, Prowle and Lowth (2013), Uyar (2010), and Sunarni (2013) descriptively revealed that product costing and budget for planning are the conventional management accounting tools useful for SME managers before 1950's up to date.

To provide need-fulfilling and offers want-fulfilling products or services, strategy implementation is important to deliver positive impact to target customers. This study determined from 400 participants whether year of business operation, business size, and management accounting tools are predictive of the business strategies group.

\section{Literature Review}

During 1970's companies had operated in a type of business system called product-focused mentality. They spend plenty of time and money for research to discover different unique features of products and focused their attention on the product process and measurement. Then, due to tight competition in the global market companies discovered and gradually converted their strategies into an intense customer-focused mentality (Atkinson et al. 2012; Fornell and Johnson, 1991). They learned to understand and provide the purchasers expectations for their products and services. Moreover, their aims were not only to provide the best products and services to attract potential customers worldwide, but also the retention of consumers. 
Foster and Young (1997) on the other hand, performed cost management seminars to 300 general managers and finance/accounting managers in two U.S. cities and four Australian municipalities. The researchers discovered that the most common nonfinancial metrics in measuring customer performance was customer satisfaction and ranked as the most important factor prioritized by the management.

Then, several researchers discovered the importance of management accounting information to owners and managers in managing their businesses. They found out that product or service cost, budgeting, break-even analysis, and working capital measures are the most important pieces of management accounting information for small-medium-sized enterprises in the United Kingdom (Lucas et al. 2013). While budget for planning and control, responsibility accounting, costvolume-profit analysis, standard costing and variance analysis, and managing customers relationship were mostly utilized by Turkish and Indonesian smallmedium-sized enterprises (Uyar, 2010; Sunarni, 2013). A review of literature suggests that traditional or conventional techniques were still important to their practice. To provide for more valuable representation not only the importance and usefulness of management accounting information, and knowing what customer value proposition that they could offer, this time it is all about the impact of using management accounting information as techniques in implementing business strategies including year of business operation and business size, be it customer intimacy, operational excellence or product leadership strategy (Garrison et al. 2015). This study searched for an indication of how well the model is able to predict and classify the correct category for each case.

\section{Methodology}

\subsection{Sampling Procedure}

The researchers had decided to get the sample of the subject from the list of establishments given by the Department of Trade and Industry (DTI, 2015) and Security and Exchange Commission (SEC, 2018) using the SEC i-Register data base per business sector: manufacturing (80), wholesale and retail trade (80); accommodation and food service activities (80), financial and insurance activities (80); and professional, scientific and technical activities (80) using purposive sampling technique (Blumberg and Schindler, 2014).

\subsection{Statistical Treatment of Data}

Multiple logistic regression allows the researchers to assess how well the set of predictor variables predicts or explains the categorical dependent variable. It gives an indication of the adequacy of the model (set of predictor variables) by 
assessing "goodness of fit". It provides the relative importance of each predictor and the interaction of among the predictor variables (Peat 2001; Tabachnick and Fidell, 2013; Wright 1995).

\section{Findings and Discussions}

Under the section Block 1, Table 1, the full model containing all predictors was statically significant, $\mathrm{X}^{2}(7, \mathrm{~N}=400)=364.78, p<.000$ for customer intimacy; $\mathrm{X}^{2}(7, \mathrm{~N}=400)=377.75, p<.000$ for operational excellence; and $\mathrm{X}^{2}(7, \mathrm{~N}=400)$ $=265.51, p<.000$ for product leadership, indicating that the model was able to distinguish between respondents who belong and not belong into customer intimacy, operational excellence, and product leadership group.

Table 1. Block 1: Method = Enter - Omnibus Tests of Model Coefficients

\begin{tabular}{|c|c|c|c|c|}
\hline \multicolumn{2}{|c|}{ Customer Intimacy } & Chi-square & df & Sig. \\
\hline \multirow[t]{3}{*}{ Step 1} & Step & 364.78 & 7 & .00 \\
\hline & Block & 364.78 & 7 & .00 \\
\hline & Model & 364.78 & 7 & .00 \\
\hline \multicolumn{2}{|c|}{ Operational Excellence } & Chi-square & $\mathrm{df}$ & Sig. \\
\hline \multirow[t]{3}{*}{ Step 1} & Step & 377.75 & 7 & .00 \\
\hline & Block & 377.75 & 7 & .00 \\
\hline & Model & 377.75 & 7 & .00 \\
\hline \multicolumn{2}{|c|}{ Product Leadership } & Chi-square & $\mathrm{df}$ & Sig. \\
\hline \multirow[t]{3}{*}{ Step 1} & Step & 265.51 & 7 & .00 \\
\hline & Block & 265.51 & 7 & .00 \\
\hline & Model & 265.51 & 7 & .00 \\
\hline
\end{tabular}

Table 2 headed as model summary shows the usefulness of the model. The Cox and Snell R Square and the Nagelkerke R Square values (Pseudo R Statistics) provide an indication of the amount of variation in the dependent variable (from a minimum value of 0 to a maximum value of 1 ). In this study, the values are 60 and .80 , suggesting that between $60 \%$ and $80 \%$ of the variability is explained by the set of variables for customer intimacy; $61 \%$ and $82 \%$ of the variability is explained by the set of variables for operational excellence; $48 \%$ and $65 \%$ of the variability is explained by the set of variable for product leadership.

Table 2. Block 1: Method = Enter - Model Summary

\begin{tabular}{lc|c|c} 
Step & -2 Log likelihood & Cox \& Snell R Square & $\begin{array}{l}\text { Nagelkerke } \\
\text { Square }\end{array}$ \\
\hline 1 Customer Intimacy & 184.44 & .60 & .80 \\
\hline 1 Operational Excellence & 168.33 & .61 & .82 \\
\hline 1 Product Leadership & 281.70 & .48 & .65 \\
\hline
\end{tabular}


Table 3 provides an indication of how well the model is able to predict the correct category for each case. The model correctly classified $90.8 \%$ of cases for customer intimacy, $95.8 \%$ for operational excellence; and $84.3 \%$ of cases for product leadership.

The sensitivity (true positive) and specificity (true negative) of the model were also calculated. The results display that the model was able to correctly classify (true positive) $90.4 \%$ of the respondents who belong to customer intimacy, $94.7 \%$, operational excellence, and $85.0 \%$ product leadership. The percentage of the group without the characteristics of interest was also correctly identified, the specificity is $91.0 \%, 96.5 \%$, and $83.2 \%$ consecutively for the respondents without customer intimacy, operational excellence, and product leadership correctly predicted not belong to customer intimacy, operation excellence, and product leadership by the model.

Table 3. Block 1: Method $=$ Enter - Classification Table $e^{a}$

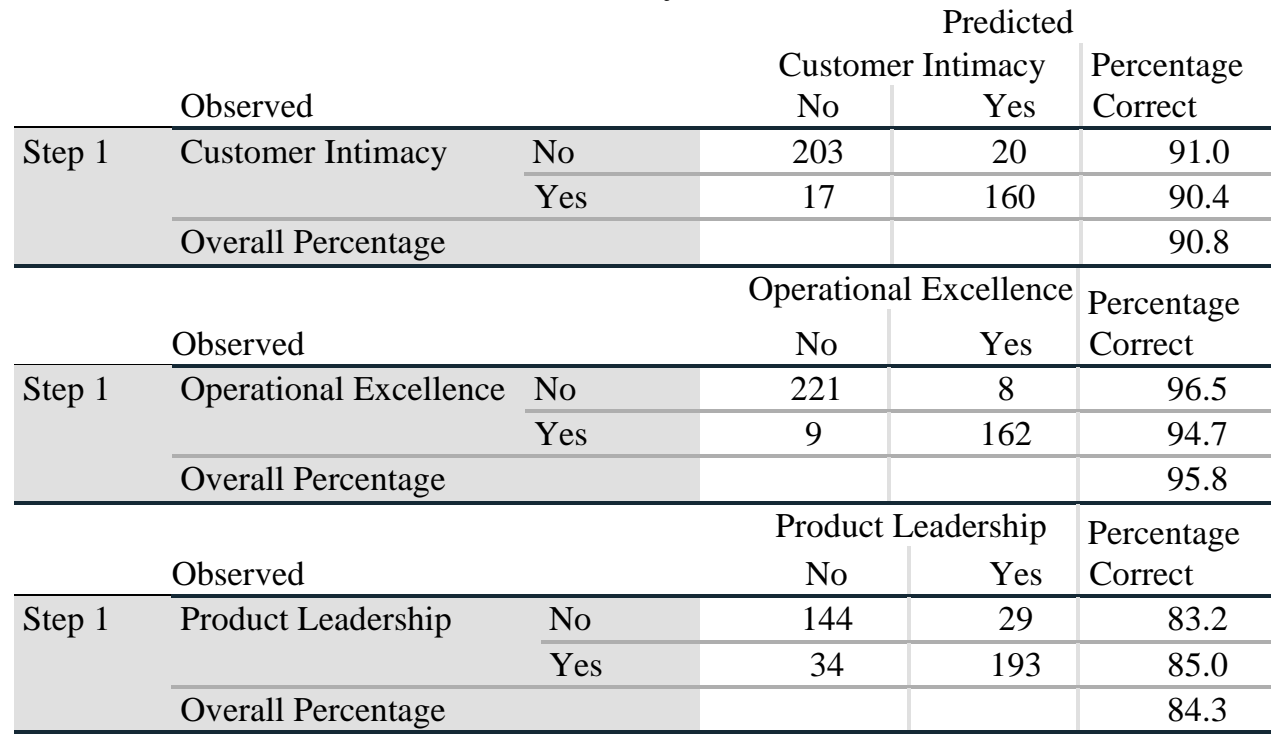

Note: a. The cut value is .500.

Table 4 provides the information about the contribution of each of the predictor variables. Looking for values less than .05 are the variables that contribute significantly to the predictive ability of the model. We have three significant variables (managing customers' relationship $p=.00$, budgeting $p=.01$, product or service cost information $p=.01$ ). These are the major factors influencing whether a respondent belongs to customer intimacy group or not, indicates that:

- For a one-unit increase in managing customers' relationship, we expect, on average, a 4.20 increase in the logit, which means as managing customers' 
relationship increases, the odds are 66.36 to 1 of being in customer intimacy group vs not, given the inclusion of business classification, year of business operation, cost-volume-profit analysis, financial statement analysis, budgeting, and product or service cost information.

- For a one-unit increase in budgeting, we expect, on average, a .45 increase in the logit, which means as budgeting increases, the odds are 1.58 to 1 of being in customer intimacy group vs not, given the inclusion of business classification, year of business operation, cost-volume-profit analysis, financial statement analysis, managing customers' relationship, and product or service cost information.

- For a one-unit increase in product or service cost information, we expect, on average, a .51 increase in the logit, which means as product or service cost information increases, the odds are 1.67 to 1 of being in customer intimacy group vs not, given the inclusion of business classification, year of business operation, cost-volume-profit analysis, financial statement analysis, managing customers' relationship, and budgeting.

Table 4. Variables in the Equation: Customer Intimacy

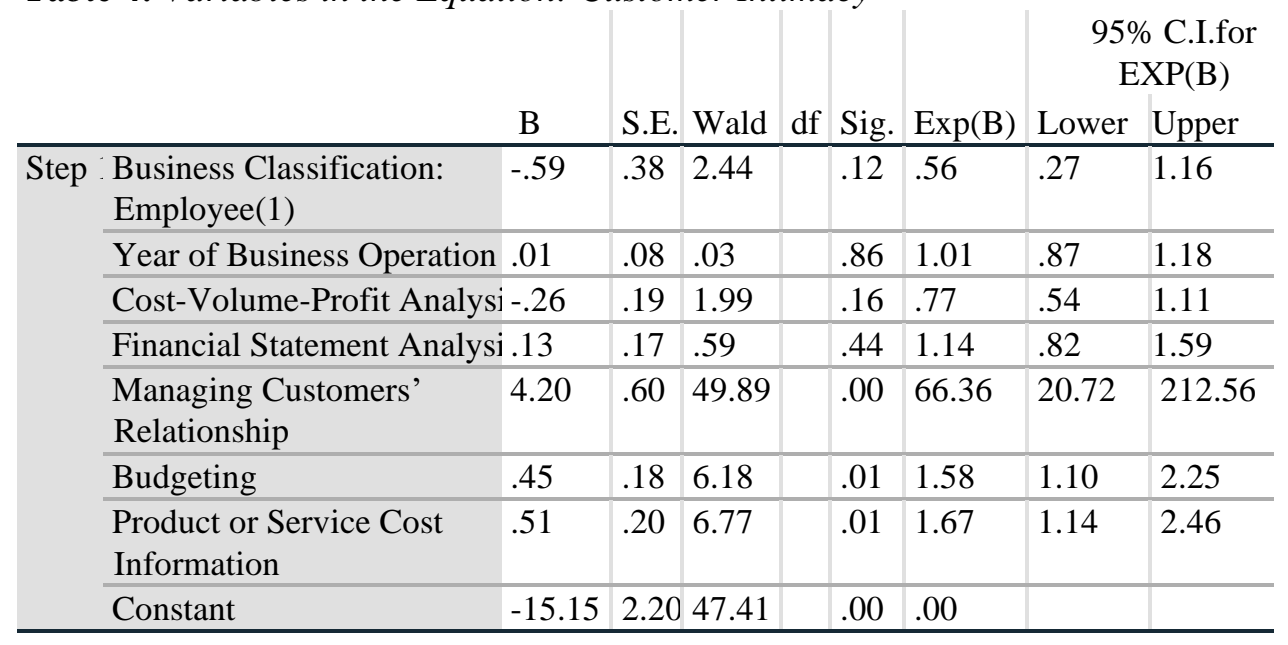

For operational excellence as shown in Table 5, we have two significant variables (budgeting $p=.00$, product or service cost information $p=.01$ ). These are the major factors influencing whether a respondent belongs to operational excellence group or not. The findings are interpreted as follows:

- For a one-unit increase in budgeting, the odds are, expectantly, 53.88 times greater of being in operational excellence group or not, which translates to a $528 \%$ increase. That is, a one-unit increase in budgeting multiplies the odds of being in operational excellence group by 53.88 . 
- For a one-unit increase in product or service cost information, the odds are, expectantly, 1.70 times greater of being in operational excellence group or not, which translates to a $70 \%$ increase. That is, a one-unit increase in budgeting multiplies the odds of being in operational excellence group by 1.70 .

Table 5. Variables in the Equation: Operational Excellence

\begin{tabular}{|c|c|c|c|c|c|c|c|c|c|}
\hline & \multirow[b]{2}{*}{$\mathrm{B}$} & \multirow[b]{2}{*}{ S.E. } & \multirow[b]{2}{*}{ Wald } & \multirow[b]{2}{*}{$\mathrm{df}$} & \multirow[b]{2}{*}{ Sig. } & \multirow[b]{2}{*}{$\operatorname{Exp}(B)$} & \multicolumn{2}{|c|}{$\begin{array}{c}\text { 95\% C.I.for } \\
\text { EXP(B) }\end{array}$} \\
\hline & & & & & & & & Lower & Upper \\
\hline \multirow[t]{8}{*}{ Step } & $\begin{array}{l}\text { Business Classification: } \\
\text { Employee(1) }\end{array}$ & -.18 & .42 & .19 & & .66 & .83 & .37 & 1.88 \\
\hline & $\begin{array}{l}\text { Year of Business } \\
\text { Operation }\end{array}$ & .00 & .09 & .00 & & .97 & 1.00 & .85 & 1.19 \\
\hline & $\begin{array}{l}\text { Cost-Volume-Profit } \\
\text { Analysis }\end{array}$ & .05 & .20 & .06 & & .80 & 1.05 & .71 & 1.55 \\
\hline & $\begin{array}{l}\text { Financial Statement } \\
\text { Analysis }\end{array}$ & .01 & .21 & .00 & & .97 & 1.01 & .66 & 1.53 \\
\hline & $\begin{array}{l}\text { Managing Customers' } \\
\text { Relationship }\end{array}$ & .25 & .18 & 1.80 & & .18 & 1.28 & .89 & 1.83 \\
\hline & Budgeting & 3.99 & .40 & 98.29 & & .00 & 53.88 & 24.50 & 118.51 \\
\hline & $\begin{array}{l}\text { Product or Service Cost } \\
\text { Information }\end{array}$ & .53 & .22 & 6.08 & & .01 & 1.70 & 1.12 & 2.59 \\
\hline & Constant & -16.57 & 2.02 & 67.43 & & .00 & .00 & & \\
\hline
\end{tabular}

Table 6 presents the information about the contribution of each of the predictor variables. Looking for values less than .05 are the variables that contribute significantly to the predictive ability of the model. Product leadership provides three significant variables. This indicates that:

- Managing customers' relationship is significant predictor, according to the Sig. value $(p=.00)$. The odds ratio for this variable, however, is .21 , a value less than 1. This indicates that the more useful the tool is the less likely of being in product leadership group, all other factors being equal.

- Budgeting is also a significant factor, according to the Sig. value $(p=.00)$. The odds ratio for this variable, however, is .19 , a value less than 1 . This indicates that the more useful the tool is the less likely of being in product leadership group, all other factors being equal.

- The fact that the odds ratio of product or service cost information is 1.49 to 1 means that as product or service cost information increases in one unit, the chance of being in product leadership group vs not is likewise greater. 
Table 6. Variables in the Equation: Product Leadership

\begin{tabular}{|c|c|c|c|c|c|c|c|c|c|}
\hline & \multirow[b]{2}{*}{$\mathrm{B}$} & \multirow[b]{2}{*}{ S.E. } & \multirow[b]{2}{*}{ Wald } & \multirow[b]{2}{*}{ df } & \multirow[b]{2}{*}{ Sig. } & \multirow[b]{2}{*}{$\operatorname{Exp}(B)$} & \multicolumn{2}{|c|}{$\begin{array}{c}\text { 95\% C.I.for } \\
\text { EXP(B) }\end{array}$} \\
\hline & & & & & & & & Lower & Upper \\
\hline \multirow[t]{8}{*}{ Step } & $\begin{array}{l}\text { Business Classification: } \\
\text { Employee(1) }\end{array}$ & .19 & .30 & .40 & & .53 & 1.21 & .67 & 2.19 \\
\hline & Year of Business Operatic & -.04 & .06 & .42 & & .52 & .96 & .85 & 1.09 \\
\hline & Cost-Volume-Profit Anal & .25 & .15 & 2.64 & & .10 & 1.28 & .95 & 1.73 \\
\hline & Financial Statement Analy & .20 & .15 & 1.88 & & .17 & 1.23 & .92 & 1.64 \\
\hline & $\begin{array}{l}\text { Managing Customers' } \\
\text { Relationship }\end{array}$ & -1.56 & .19 & 70.19 & & .00 & .21 & .15 & .30 \\
\hline & Budgeting & -1.68 & .20 & 71.74 & & .00 & .19 & .13 & .28 \\
\hline & $\begin{array}{l}\text { Product or Service Cost } \\
\text { Information }\end{array}$ & .40 & .17 & 5.39 & & .02 & 1.49 & 1.06 & 2.08 \\
\hline & Constant & 7.93 & 1.10 & 52.40 & & .00 & 2783.18 & & \\
\hline
\end{tabular}

The 95\% confidence interval (CI) displayed, having a lower value and an upper value was the range of values that we can be 95 percent confident about the true value of the odds ratio.

\section{Conclusions and Recommendation}

The study revealed that managing customers' relationship, product or service cost information, and budgeting are aligned factors for the companies that adopt a customer intimacy strategy. The more useful the management accounting techniques, the more it is effective for the companies to understand and respond to their targeted customers needs. The ideas can help the start-up small and medium enterprises to directly focus their resources and rely more use of managing customer relationship first because among the three set of significant variables, it is the best predictor of the outcome. Managers need to understand the common customer metrics such as: customer satisfaction and loyalty that could serve as the leading indicator of future revenue and profit performance. Specifically, for the service companies namely: accommodation and food service activities, financial and insurance activities, and professional, scientific and technical activities.

However, excessive focus on improving customers' relationship can lead into loss of performance. Because too much giving of discounts, customer service, and other freebies can increase the risk of going beyond the goal of meeting the objectives. That is why product or service cost information and budgeting are also significant to balance the pressure on how much price to charge. Measuring the cost and profit earned provide valuable balancing financial measures. 
On the other hand, budgeting and product or service cost information are the factors for the companies that adopt operational excellence strategy. Measuring product or service cost is a small part of the overall budget. That is why budgeting is the best predictor between them because offering the product and service in a faster and at a lower price than competitors might lead into loss of performance. It is useful to at least the company should start measuring the resource consumption and costing then, matched with the expected revenue to determine if there is profit or loss for the period. Through this, managers can discover high-cost and inefficient process to improve and make the business operations better. Managers of service companies must focus more than manufacturing companies due to the variation in demand of customers. Manufacturing company can use standardized cost in computing the cost of making the products without regards on how the customer use them. Service companies are more customer dependent in contrast with the manufacturing cost which is customer independent.

Lastly, product or service cost information provides direct relationship in which the factor increase the likelihood of yes answer than budgeting and managing customers' relationship in which the factors decrease it, although all of the three factors are significant for the company that adopt product leadership strategy. Among the kinds of customer value proposition, offering higher quality products produced contradicting results. One usually outweighs the other factors in terms of its usefulness. This means that the use of product or service cost information supports more than what other two factors can contribute in terms of product leadership. The factor gives more emphasis about the importance of price in relation to quality. Companies that adopt product leadership strategy are already familiar about the impact on cost when increasing the technical aspects of product design and performance specifications to satisfy customer expectations.

Therefore, this study shows how important the product or service cost information because it consistently supports the needs of the firms whether the companies adopt customer intimacy, operational excellence, and product leadership. Consistent from the findings made by Lucas et al. (2013), Uyar (2010), and Sunarni (2013) that product and service cost information is the conventional management accounting tools useful for SME managers before 1950's up to date. Also, more management accounting tools produced direct relationship and significant contributions in predicting customer intimacy compared to operational excellence and product leadership strategy group.

The findings proved that management accounting enhances the planning and controlling process of the business, agency theory influences the direction of the business and contingency theory truly supports that the appropriateness of management accounting information system depends upon the size, operating 
activities and strategies. Attribution theory supports that the impact of individual behavior influences the owners, accountants, and managers' managerial assumptions of the business. If managers' effort today provides greater attention on customer intimacy, how do companies determine the peoples' product and service preferences to meet and satisfy their needs? These are the challenges for small-medium-sized company owners, accountant, and managers that they need to consider in entering into large-sized or in a global market in order to have long-term sustainable success.

\section{References:}

Atkinson, A., Kaplan, R., Matsumura, E., Young, M. 2012. Management accounting: information for decision-making and strategy execution $\left(6^{\text {th }}\right.$ ed.). England, Pearson Education Ltd.

Blumberg, D., Cooper, D., Schindler, P. 2014. Business research methods ( $4^{\text {th }}$ ed). Asia, McGraw-Hill.

Cole, G. 2004. Management theory and practice (6th ed.). London: Thompson Learning.

Department of Trade and Industry Philippines. 2015. Entrepreneurs in Metro Manila. Retrieved from http://dtincr.ph/news.php?id=6>.

Fornell, C., Johnson, M.D. 1991. A framework for comparing customer satisfaction across individuals and product categories. Journal of Economic Psychology, 12, 267286.

Foster, G., Young, M. 1997. Frontiers of management accounting research. Journal of Management Accounting Research 9, 63-77.

Garrison, R., Noreen, E., Brewer, P., Sang Cheng, N., Yuen, K. 2015. Managerial accounting. Asian global edition ( $2^{\text {nd }}$ ed). Asia, McGraw-Hill Education.

Lucas, M., Prowle, M., Lowth, G. 2013. Management accounting practices of UK smallmedium-sized enterprises. Improving SME performance through management accounting education. Journal of Chartered Institute of Management Accountants, $9(4), 1-13$.

Peat, J. 2001. Health science research: A hand-book of quantitative methods. Sydney, Allen \& Unwin.

Scapens, R. 2006. Understanding management accounting practices: A personal journey. The British Accounting Review, 38(1), 1-30.

Security and Exchange Commission. 2018. List of Sec Registered Corporations within Metro Manila from 2005-2016, SEC i-Register database.

Sunarni, C. 2013. Management accounting practices and the role of management accountant: evidence from manufacturing companies throughout Yogyakarta, Indonesia, Review of Integrative Business and Economic Research, 2(2), 616-626.

Tabachnick, B.G., Fidell, L.S. 2013. Using multivariate statistics $\left(6^{\text {th }}\right.$ ed $)$. Boston, Pearson Education.

Uyar, A. 2010. Cost and management accounting practices: a survey of manufacturing companies, Eurasian Journal of Business and Economics, 3(6), 113-125.

Wright, R.E. 1995. Logistic regression: Reading and understanding multivariate statistics. Washington, DC, American Psychological Association. 